\title{
Goodness of Cloud Computing: does Bangladesh ready for it
}

\author{
Md. Ahsan ul Hasan
}

Lecturer, MIS, ASA University Bangladesh

\begin{abstract}
Technology is playing a vital role in all aspect of our lives. Last decade has seen information and communication technologies dramatically transforming the world, enabling innovation and productivity increases, connecting people and communities, and improving standards of living and opportunities across the world. Even though global economy has been turbulent during last several years, governments and organizations trying to keep the momentum going and last couple of years "Cloud Computing" becoming fast-growing technology phenomenon. Cloud Computing can provide fundamental contribution to efficiency in public and private sectors as well as it can also promote growth, competition and business creation. The purpose of this study is to portrait whether developing countries like Bangladesh can be benefited from cloud computing, and also finds out Bangladesh's readiness to take full advantage of it.
\end{abstract}

Key Words: Cloud Computing, Clouds, Internet, Virtual desktop.

JEL Classification Code: L86; C89

\section{INTRODUCTION}

The IT services, which are known as cloud computing these days, have been around for decades. But they never grew beyond a small fraction of total industry revenue. But the scenario changes last couple of years; a dizzying array of hardware and software available for services over the Internet has emerged. Consumers and businesses have embraced a multitude of cloud services, from large sales force management services to email and photo editing to the latest smart phone applications and the entire social networking phenomenon. Research firm International Data Corporation (IDC) calls cloud computing the foundation for the technology industry's next 20 years of growth, saying "it is nothing less than the complete transformation of the industry's core offering and business models. According to IDC, cloud computing will grow at a compound annual rate of about $26 \%$ for the next couple of year which is roughly five times the growth rate of the technology industry as a whole. In addition, $80 \%$ of all new software offerings in the upcoming years will be available as cloud services (Global Technology Industry, 2011). Giant technology companies like Google, Microsoft, Amazon, HP, IBM are investing heavily for this technology. 
Even though cloud computing around us for years, In Bangladesh it is still a new concept. At the moment there is pretty little awareness about cloud computing. However, this situation is changing bit by bit. Bangladesh's software and IT service industry has crossed long road over the last decade and started to contribute to the country's economy. One of the distinctive features of Bangladesh's IT industry is the presence of young entrepreneurs. Despite various local and global challenges, these young entrepreneurs have done remarkably well in building sustainable business organization through their dedication and passion for this field. These passionate IT professionals and clouds promises to lower cost and faster deployment than traditional IT makes Bangladesh a potential country to compete in cloud computing services with developed countries.

\section{ObJectives OF The Study}

Cloud computing and virtualization promises lower cost and faster deployment than traditional IT, and developing countries like Bangladesh can be benefited from it. The main focuses of this study are as follows:

- To understand cloud computing

- To identify the benefits that Bangladesh will get by implementing Cloud Computing

- To examine Bangladesh's current IT industry and find out its readiness to get full advantage of cloud computing.

\section{Methodology OF THE STUdY}

This study is mainly based on secondary data. These data have been collected from different published materials like the publication of World Economic Forum, Bangladesh Association of Software and Information Services (BASIS), Bangladesh Bureau of Statistics, Bangladesh Computer Council and relevant writings from different scholars.

\section{LIMITATIONS OF THE STUDY}

Although this research was carefully prepared, there are some limitations and shortcomings. The major limitation of this study is resource constrains as cloud computing is still a new concept Even though all data has been taken from reliable sources yet lack of up-to-date data on Information Technology in Bangladesh was a great drawback of this study.

\section{Overview of Cloud Computing}

The term cloud has been used as a metaphor for the Internet. Cloud computing is the use of computing resources that are delivered as a service over a network. This technology provides service to the customer to access large scale of data. Cloud computing entrusts remote services with user's data, software and computation. According to the US National Institute of standards and Technology (NIST)(Mell \& Grance, 2011) "cloud computing is a model for enabling convenient, on-demand network access to shared pool of configurable computing resources (e.g., networks, web servers, storage, applications and services) that can be rapidly provisioned and released with minimal management effort or service provider interaction". A cloud computing platform dynamically provisions, configures, reconfigures, and depravations servers as needed. Servers in the cloud can be physically machines or virtual machines. Advanced clouds can also include other computing 
resources such as Storage Area Network ${ }^{1}$ (SANs), Network Equipment, Firewall and other security devices. Anyone with a suitable internet connection and standard browser can access a cloud application. Depending on services cloud computing can be divided into four types (Amies et al., 2012), and they are:

- Infrastructure as a service (IaaS) also referred to as Resource Clouds, provide resources as services to the user. This type of cloud provides enhanced virtualization capabilities. To deploy this application, cloud users install operating-system images and their application software on the cloud infrastructure. In this model, the cloud user patches and maintains the operating systems and the application software.

- Platform as a Service (PaaS) provide computational resources via a platform upon which applications and services can be developed and hosted. PaaS typically makes use of dedicated Application Programming Interface (API) to control the behavior of a serverhosting engine, which executes and replicates the execution according to user requests.

- Software as a Service (SaaS) also known as Service Cloud or Application Cloud, offers specific business functions and business processes with specific cloud capabilities. It provides applications/services using a cloud infrastructure or platform, rather than providing cloud features themselves.

Clouds may be hosted and employed in different fashions, depending on the use case or business model of the provider. There has been a tendency of clouds to evolve from internal solutions to manage the local infrastructure and the amount of requests. Depending on usages there are several types of cloud available and each bringing its own specific implications for its users (The European Union, 2010). The main variants are:

- Private Clouds is cloud infrastructure operated solely for a single organization, whether managed internally or by a third-party and internally or externally. Private clouds functionalities may not directly exposed to the customer, but sometimes services with cloud enhanced features may be offered.

- Public Clouds provides applications, storage, and other resources available to the general public by a service provider. These services are mostly free or offered on a pay-per-use model. Generally public cloud providers offer access to their user via internet.

- Community Cloud shares infrastructure between several organizations with common concerns like security, compliance, jurisdiction, etc from specific community. Community cloud can be managed internally or by a third-party. It can also be hosted internally or externally.

- Hybrid Cloud is a composition of two or more clouds that remain unique entities but are bound together and offering the benefits of multiple deployment models. Hybrid clouds are able to obtain degrees of fault tolerance combined with locally immediate usability without dependency on connectivity.

\section{BENEFITS THAT CLOUD COMPUTING CAN OFFER TO A COUNTRY LIKE BANGLADESH}

Despite an unfavorable global economy, Bangladesh is rapidly developing market-based economy. Bangladesh manages to grown its economy at the rate of $6-7 \%$ per annum over the past few years and is expected to reach 6 percent in fiscal 2013(The World Bank, 2012).

\footnotetext{
${ }^{1}$ Storage Area Network (SAN) is a dedicated network that provides access to consolidated, block level data storage. SANs are primarily used to make storage devices, such as disk arrays, tape libraries, and optical jukeboxes, accessible to servers so that the devices appear like locally attached devices to the operating system.
} 
According to the International Monetary Fund (IMF), Bangladesh ranked $44^{\text {th }}$ largest economy in the world in PPP terms and 57th largest in normal terms. More than half of the GDP is generated by the service sector (Wikipedia, 2013). According to the GDP data of Bangladesh Bureau of Statistics (BBS) in FY 2010-11, the contribution of the manufacturing sector to GDP at the constant price is 18.41 percent (Economic Adviser's Wing, 2012). Bangladesh government wants to be consistent with the imperative and they are creating favorable policy for the promotion of cottage, small and medium industries (SMEs) along with large-scale industries. To this end, Cloud Computing can help government in this cause as cloud computing promises lower cost and faster deployment than traditional IT. Moreover, developing countries like Bangladesh, where labor-intensive industries are more suited than capital-intensive industries, have little money to spend on and no time to lose. To grow SME as well as largescale industry in Bangladesh, cloud computing can provide following benefits:

- Cost Savings: as most businesses in Bangladesh are fall short of providing proper resources to meet growing business needs and in this current economic situation companies are forced to shrink their IT budgets. Therefore, businesses are forced to focus on optimizing every resource within their infrastructure. The beauty of cloud services is that they inspire businesses to not to spend out on hardware, software and even license fee as all the heavy lifting is done by the cloud application developer. Moreover, businesses do not need to employ additional IT staff to deal with any problems which might arise as services are completely managed by the service providers.

- Greater Business Agility: revolution in communication technology means that business now can be done anywhere where there is Internet. Cloud computing allows businesses to take full advantage of this opportunity. Cloud based mobility solutions enable its customer to take their business into the audience effectively and also permit to access their files and applications regardless where they are.

- Subscription-based pricing: one of the key feature of cloud computing is its services are customize able and they offer the option to pay monthly. Subscription-based pricing helps businesses to access incredibly sophisticated software with no upfront fees with no lock-in periods. As a result, businesses in Bangladesh mainly SMEs can access powerful software and services for a fraction of the cost of buying or developing it in-house.

- Keeping Up-To-Date: to survive cloud business, cloud services constantly upgrade its services. There are hardly any interruptions to service and businesses don't have to search for new versions of the software every few years.

- Speedy Implementation: with cloud computing services there is no need to purchase hardware or software, which means systems can be up and running in the time it takes to enter the business information and payment details.

- Safe and Security: A reputable cloud provider always try to make sure that its customers data is encrypted and backed up, which takes the pressure and costs associated with data back-up away from businesses. It also takes away the worry of the businesses having to consider in-house data security as this is passed to the cloud provider.

- Increasing Efficiency: Cloud services can enable businesses to significantly streamline the way in which they work, from sharing resources in one place to having the ability to collaborate in ways previously not possible.

- Environmentally friendly: Recent studies show cloud technology could reduce company carbon emissions by up to $50 \%$, which is great news and as it reduces the reliance on outmoded On-premise systems as everything is done via the cloud.(Accenture, 2011) 
Businesses, especially in countries like Bangladesh face a tough challenge of meeting growing demands with very limited resources. And it is evident that Cloud Computing has something to offer every business from cottage to heavy industries. Right from application delivery to mobility solutions, cloud computing offers an intuitive methodology to leverage resources and improve business performance. Therefore, there is no doubt that implementing cloud computing will help Bangladesh's cause to create "Digital Bangladesh" sooner than later.

\section{BANGLADESH'S READINESS TO ADOPT CLOUd}

As it is proven that implementing cloud will help grow developing economy, question arises when a developing country like Bangladesh tries to implement a new technology is whether they have enough resources or skills to develop or maintain. Generally there are two ways, a) developing own cloud, b) subscribing from others. Almost all the powerhouses of IT companies are heavily investing on cloud computing. Government agencies in developing economies like India, china are also focusing on cloud computing regarding the potential and impact. Either way it requires skilled IT personnel and a good ICT infrastructure. To determine Bangladesh's readiness following factors are considered:

- IT Industries of Bangladesh: IT industries in Bangladesh started to grow around 2000 and it has matured over the past few years. According to the survey of Bangladesh Association of Software And Information Services (BASIS), there are over 800registered software (BASIS, 2012) and IT Enabled Service (ITES) companies in Bangladesh. There are another few hundred of unregistered small and home-based software and IT ventures doing business for both local and international markets and about $70 \%$ of the companies involved in development and maintenance of software for their clients. Bangladesh Association of Software and Information Services (BASIS) survey also show that almost half of the companies are involved in providing range of IT enabled services. Another survey (Shinkai \& Hossain, 2011) says that more than 20 per cent are exporting their products and services to over 30 countries. Among these, over 20 per cent companies have obtained ISO certification and a number of companies are in the process of acquiring CMMI (Capability Maturity Model Integration $)^{2}$ certification and at least six companies have achieved CMMI level 3.

As cloud computing depend on Internet, one of the most encouraging recent trends in the Bangladeshi IT industry is that, around $45 \%$ are focusing or diversifying on different web based services that include specialized portals, listing services, eCommerce etc. Moreover, in today's challenging economic conditions, Bangladesh has positioned itself as a key location for consideration by enhancing delivery capability and skill availability, lower costs of operations.

\footnotetext{
${ }^{2}$ Capability Maturity Model Integration (CMMI) is a process improvement training and certification program and service administered and marketed by Carnegie Mellon University. There are five maturity levels, and Level 5 being the height.
} 
Chart: Business Specialization of BASIS Member Companies

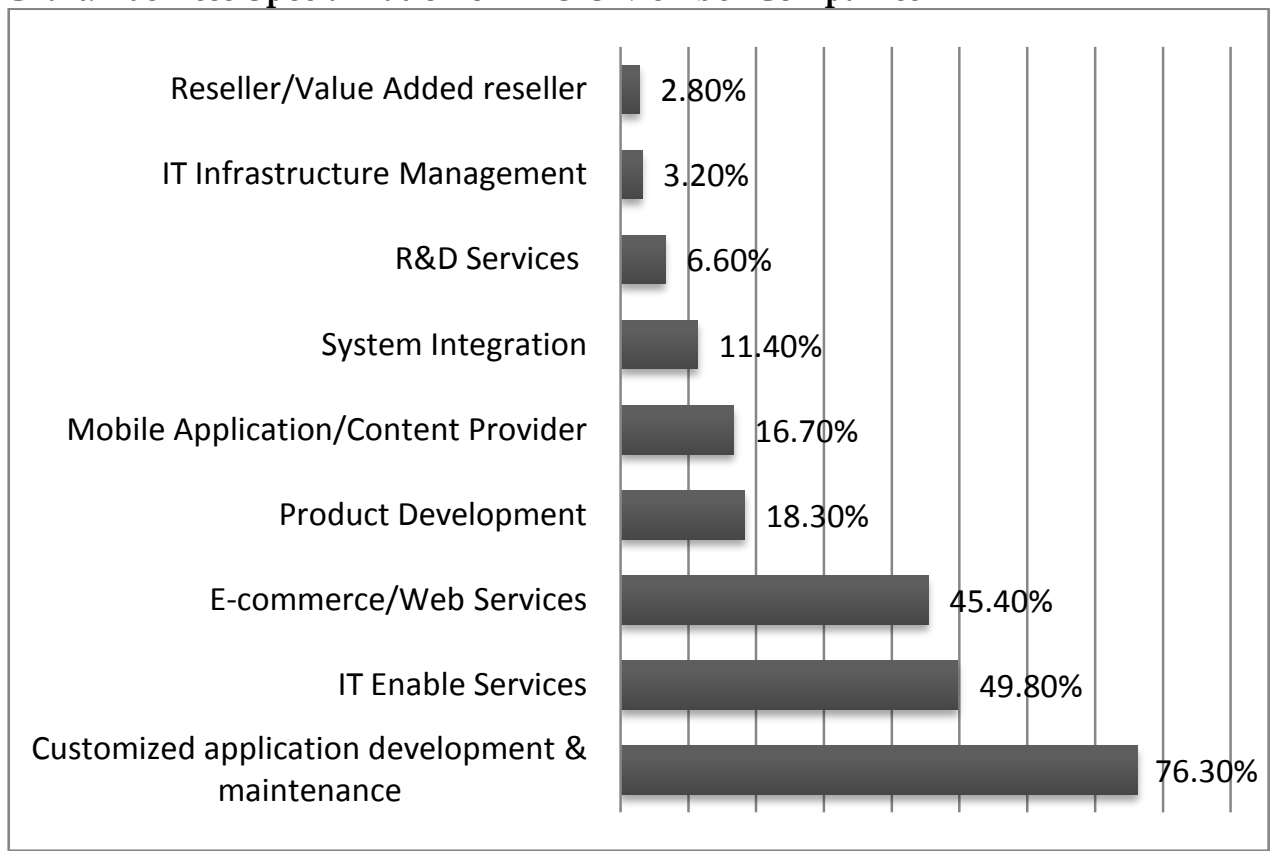

Source: Bangladesh Association of Software and Information Services (BASIS) survey

- Skilled professionals: Bangladesh has a huge source of skilled human resources with its cultural adoption capability, English language skills, and a large number of educated and energetic youths with bright aptitude, and natural ability in software development. It also offers relatively low cost. Study shows that the costs are almost $40 \%$ lower than established destinations like India or Philippines (KPMG Bangladesh, 2012). Moreover, depending on theoretical and experimental evidence, skill level is closely associated with the performance of firms. An important prerequisite for the development of IT sector depends on the availability of skilled workforce with cheaper wage rate.

\section{Table: Skill level for Particular Activity}

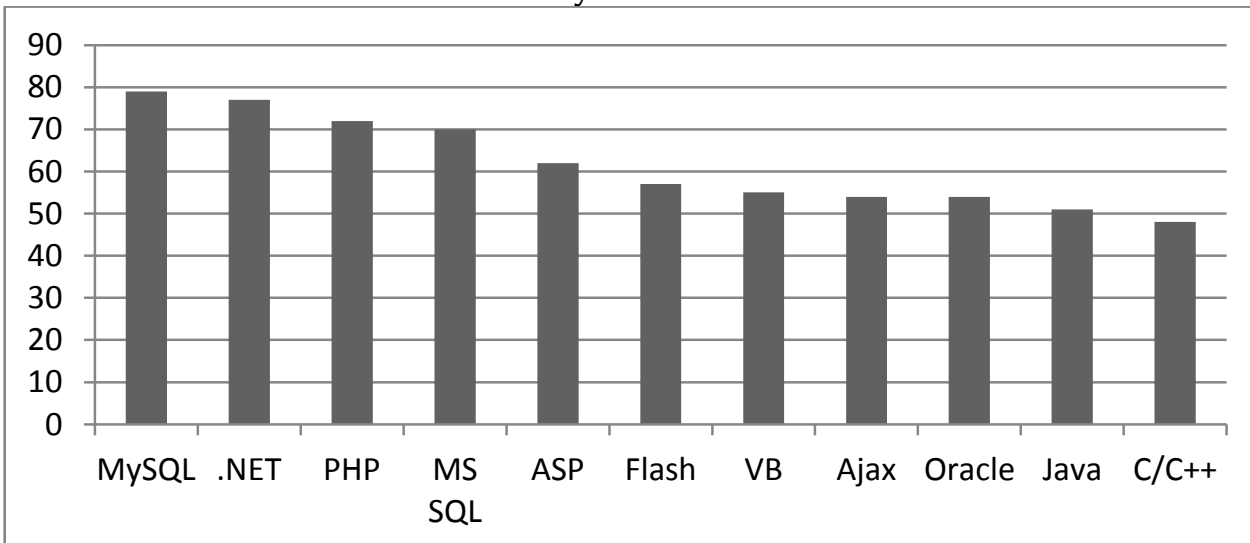

Source: Bangladesh Association of Software and Information Services Survey 2012 
According to BASIS survey approximately 30,000 professionals are employed in the industry. Even though the contribution for overall employment creation is not significantly high, it is creating high quality employment with average monthly compensation over Tk. 15,000 per month, which making software and IT service industry one of the top graduate employment sectors in the country. Almost all top institutes offer Computer Science or IT related program and it has been one of the favorite programs among students. These tech savvy, spirited young graduates are continuously participating international programming contest and performing relatively well. As a result many global players like Samsung, AMD, VizRT, WorldBridge Global and most recently Google - setting up operations in Bangladesh. All this evidence proves that Bangladesh have the skilled personnel to tackle IT challenges.

- Infrastructure readiness: Cloud Computing is 100 percent relay on Internet. The cloud model for computing storage and network resource management require distributed computing architecture and also require strong and fast network to handle increasing volume of data traffic. Bangladesh straggles in this area. The Networked Readiness Index published in Global Information Technology report 2012 by World Economic Forum, Bangladesh placed 113 out of 142 countries scoring 3.20 suggest Bangladesh's weakness. However, ICT has been declared as the thrust sector by the Government and situation is changing. The table shows the slow but increasing tendency of the development of ICT in Bangladesh over past few years.

Table: ICT Development Indicators In Bangladesh

\begin{tabular}{|l|l|l|l|l|}
\cline { 2 - 5 } & $\mathbf{2 0 0 9}$ & $\mathbf{2 0 1 0}$ & $\mathbf{2 0 1 1}$ & $\mathbf{2 0 1 2}$ \\
\hline Internet users (per 100 people) & 0.32 & 0.35 & 0.4 & 3.7 \\
\hline Secure Internet Servers (per 1 million people) & 0.4 & 0.9 & 0.2 & 0.3 \\
\hline Mobile phone subscriptions (per 100 people) & 21.66 & 27.90 & 32.3 & 46.2 \\
\hline Broadband internet subscriptions (per 100 people) & 0.0 & 0.03 & 0.04 & 0.06 \\
\hline Int'1 Internet bandwidth (mbps per user) & 0.09 & 0.4 & 1.2 & 2.8 \\
\hline Electricity production (kWh per capita) & 147.72 & 156.03 & 154.5 & 240.3 \\
\hline Broadband internet tariffs (PPP\$min) & 1028.74 & 155.06 & 128.8 & 36.28 \\
\hline Mobile cellular Tariffs (PPP\$min) & 0.31 & 0.08 & 0.07 & 0.03 \\
\hline Mobile network coverage, (per 100 people) & -- & -- & 90 & 90 \\
\hline
\end{tabular}

Source: Global Information Technology Report, 2009 to 2012

All these evidence proves that, even though Bangladesh's software and IT services came long way from where it was a decade ago, yet it still have long way to go. The IT industries in Bangladesh are more than capable to develop and provide cloud services as it has skilled, energetic and relatively inexpensive IT professional. However, it is evident (from above table) that current IT infrastructure is not ideal for deploying cloud computing in Bangladesh as the internet service in Bangladesh is expensive and also it is not adequate enough to take the heavy load that cloud requires.

\section{Concluding Remark}

The rapid changes that the ICT industry has experienced in the last decade have brought about deep transformations in the way our economic activity and society are organized. There is a sense of immediateness and constant accessibility is redefining the relationships 
between and across individuals, business, and governments. It has been predicted that the IT and telecommunications industries will converge for cloud services. In addition to providing bandwidths for cloud services, telecommunications carriers will gradually move their IT systems, value-added services, and internet data centers into the cloud to provide services to a variety of industries. This study proves that cloud computing will make sizable contribution to countries economy, even small developing economies like Bangladesh. However, this study also point out that Bangladesh lacks financial power as well as proper infrastructure for a wide and deep adoption of cloud. Another problem that has been point out is Bangladesh's approach towards Internet use. According to the Global Information Technology report, 2012 only 3.7\% of its population use Internet services. Yet, the situation in Bangladesh is improving, slowly but surely. Few IT Pioneers of Bangladesh joined the Oracle CloudWorld to look for new solutions to serve their clients more efficiently and sustain in the competitive business. Bangladesh government also have identified the prospect of cloud computing. Bangladesh Computer Council (BCC), an agency dedicated to improving the state of the Information Technology in the country taking initiatives to move toward cloud computing.

It would be unreasonable to expect that the cloud would help small economy like Bangladesh to catch up with the advanced economy. However, if the Bangladesh government properly undertakes policies to create a "Digital Bangladesh" as laid down in its perspective plan, the Cloud Computing certainly holds a promise to minimize the divide.

\section{References}

[1] Accenture, 2011. Cloud Computing and Sustainability: The Environmental Benefits of Moving to the cloud. [Online] Available at: http://www.accenture.com/SiteCollectionDocuments/PDF/Accenture_Sustainabili ty_Cloud_Computing_TheEnvironmentalBenefitsofMovingtotheCloud.pdf [Accessed 05 April 2013].

[2] Amies, A., Sluiman, H., Tong, Q.G. \& Liu, G.N., 2012. Developing and Hosting Applications on the Cloud. Indiana: IBM Press.

[3] BASIS, 2012. Bangladesh Association of Software $\mathcal{E}$ Information Services. [Online] Available at: http://www.basis.org.bd/index.php/resource [Accessed 05 May 2013].

[4] Dutta, S. \& Bilbao-Osorio, B., 2012. Global Information Technology Report 2012. Insight Report. Geneva: World Economic Forum World Economic Forum and INSEAD.

[5] Dutta, S. \& Mia, I., 2009. Global Information Technology Report 2008-2009. Insight Report. Geneva: World Economic Forum World Economic Forum And INSEAD.

[6] Dutta, S. \& Mia, I., 2010. Global Information Technology Report 2009-2010. Insight Report. Geneva: World Economic Forum World Economic Forum and INSEAD.

[7] Dutta, S. \& Mia, I., 2011. Global Information Technology Report 2010-2011. Insight Report. Geneva: World Economic Forum World Economic Forum and INSEAD.

[8] Economic Adviser's Wing, 2012. Bangladesh Economic Review - Finance Division. [Online] Available at: http:/ / www.mof.gov.bd/en/index.php?option=com_content\&view=article\&id=211 \&Itemid=1 [Accessed 05 April 2013].

[9] Edwards, J., 2012. Cloud computing for SMEs. [Online] Available at: http://www.bmmagazine.co.uk/in-business/advice/13552/cloud-computing-forsmes/ [Accessed 02 April 2013]. 
[10] Evans, P., 2012. Bangladesh - Internet Market and Forecasts. [Online] Available at: http://www.internetworldstats.com/asia/bd.htm [Accessed 03 April 2013].

[11] Global Technology Industry, 2011. Cloud Computing Issues and Impacts. UK: Ernst \& Young IT Organization.

[12] Hossain , M. \& Shinkai, N., 2011. Integration of ICT Industries and Its Impact on Market Access and Trade: the Case of Bangladesh and India. South Asia Network of Economic Institutes, pp.11-16.

[13] KPMG Bangladesh, 2012. Bangladesh Beckons, An emerging destination for IT/ITeS Outsourcing. Amstelveen: KPMG International.

[14] Mell, P. \& Grance, T., 2011. The NIST Definition of Cloud. Gaithersburg: National Institute of Standards and Technology.

[15] Richards, J., 2013. Benefits of Cloud Computing for SMEs. [Online] Available at: http:/ / www.techbubbles.co.uk/blog/10-benefits-of-cloud-computing-for-smes/ [Accessed 02 April 2013].

[16] Shinkai, N. \& Hossain, M., 2011. Productivity and Performance of IT Sector in Bangladesh: Evidence from the Firm Level Data. Bangladesh Development Studies Vol. June 2011, No.2 ,XXXIV(2), pp.1-12.

[17] The European Union, 2010. The Future of Cloud Computing- Opportunities for Europeran Cloud Computing Beyond 2010. EU: The Publications Office of the European Union.

[18] The World Bank, 2012. Bangladesh Economic Update. [Online] Available at: http:/ / documents.worldbank.org/curated/en/2012/10/16847978/bangladesheconomic-update [Accessed 05 April 2013].

[19] Wikipedia, 2013. Economy of Bangladesh. [Online] Available at: http://en.wikipedia.org/wiki/Economy_of_Bangladesh [Accessed 05 April 2013].

[20] World Bank , 2012. INTERNET USERS IN BANGLADESH. [Online] Available at: http://www.tradingeconomics.com/bangladesh/internet-users-wb-data.html [Accessed 03 April 2013]. 